\title{
Risk Status of Malaria Based on Socio-Demographic and Environmental Risk Factors in Two Communities in Lagos, Nigeria
}

Abdulrahman Babatunde Bello ( $\sim$ bellobabatunde9@gmail.com )

University of Ibadan https://orcid.org/0000-0002-1825-5365

\section{Research Article}

Keywords: sociodemographic factors, malaria infection occurrence, environment, risk status of malaria

Posted Date: May 19th, 2021

DOI: https://doi.org/10.21203/rs.3.rs-488751/v1

License: (9) (1) This work is licensed under a Creative Commons Attribution 4.0 International License. Read Full License 


\section{Abstract}

Studies highlighting the influence of sociodemographic, cultural and environmental factors on malaria incidence have been able to elucidate the risk status of malaria. The sociodemographic, cultural and environmental risk variables influencing malaria occurrence was evaluated.

Blood samples were collected from 360 multistage systematically selected household heads in Epe and Orimedu. Pretested and structured questionnaires were administered to the participants to obtain data related to their sociodemography, mosquito prevention practices and environmental factors of vulnerability to malaria.

Potential risk factors for malaria infection occurrence was analyzed using binary logistic regression (Odds Ratio, O.R). Chisquare $\left(X^{2}\right)$ was used to analyze the relationship between malaria outcome and bednet ownership, standard mosquito prevention practices awareness, presence of surrounding stagnant pools and possession of window/door nets.

Malaria risk was relatively high among participants aged 60 years and above $(0 . R=1.35)$, secondary school leavers ( $O . R=2.51)$, pensioners ( $(. R=3.00)$, participants without previous episodes (1.33) and participants who are not aware of malaria $(0 . R=2.11)$. Low malaria risk was observed among participants: who sought treatment in health facilities $(O . R=0.00)$ and who knew that malaria can be prevented $(O . R=0.54)$. Malaria prevalence was high among participants who own bednet(s) $\left(\bar{x}^{2}(3)=1.81, P 0.57>0.05\right)$, have windows $/$ door nets $\left(\bar{x}^{2}(3)=2.33\right.$, $P 0.95>0.05)$ and who do not have surroundings stagnant pools $\left(\bar{X}^{2}(3)=1.17, \mathrm{P} 0.33>0.05\right)$.

Age, educational level, occupation, previous malaria episodes, treatment facility of choice, malaria awareness and knowledge about mosquito prevention practices influence malaria risk status. However, bed net ownership, possession of window/door nets and absence of surrounding puddles do not significantly reduce malaria incidence.

\section{Introduction}

Malaria infection occurrence is a function of the sociodemographic, cultural and environmental conditions in a particular geographic area (Dawaki et al., 2016; Bello et al., 2017; Nwaneli et al., 2020). These factors influence risk status of malaria, level of susceptibility, social interaction as well as behaviours, thereby promoting the disease occurrence by creating favourable environment for the malaria vectors to thrive (Ernst et al., 2006). The concept of human ecology of disease has since been a principal constituent in geographic approach to study the predisposing factors towards disease in human society (Pascual et al., 2006; Ernst et al., 2009 Peterson et al., 2009). The human ecology entails the various manners in which human behaviour in its sociodemographic and cultural perspectives interact with the environment to promote or hinder the occurrence of malaria among susceptible host.

The socio-economic status, housing conditions, educational level have significant impact on the risk status of malaria. For instance, people living in close proximity, about $450 \mathrm{~m}$ away from vector breeding sites, incessant or recent migration to malaria endemic regions, weedy surroundings, houses without ceilings, houses with a separate kitchen building, living within $200 \mathrm{~m}$ of a maize field and household in which the heads had no formal education are all at an increased risk of malaria infection in the highlands (Ernst et al., 2009; Peterson et al., 
2009). The relationships that exist between urbanization and status and the prevalence of malaria cannot be over-emphasized (Jamison et al., 1993).

The chances of man to become infected with malaria mainly depend on how his behavioural traits influence the degree of human-vector contact (Ojiezeh, 2010). Human occupation, farming practices, socio-demographic factors, all have strong influence on the transmission of malaria (Tolulope, 2014; Adepoju and Akpan, 2017). For instance, the geographic location and type of human habitation in relation to the availability of vector breeding habitats, night migration in malaria endemic regions, outdoor sleeping and occupation such as night guards, level of compliance to the implementation of available malaria intervention programs, such as sleeping under the LLINs, all have influence on the presence or absence of malaria infections (Ojiezeh, 2010).

The body mass of a host may also affect malaria risk status by influencing host selection, with a larger host tending to exude a higher quantity of olfactory cues thereby increasing the attractiveness of the vector to human. A study reported that the production of metabolic carbon dioxide is positively associated with body size (Torr et al., 2006), which may in turn influence host selection by the vector. According to Havlicek et al. (2005), young children are less frequently bitten by mosquitoes compared with adult parents, due to mosquitoes expressing different degrees of preferences for humans in terms of odour profile, age, gender, among others.

Since malaria risk status has been established to vary from one geographic region to another, and is dependent on the prevailing sociocultural, economic, demographic and environmental risk variables, adoption of targeted allocation of malaria intervention strategy, in order to ensure that interventions get to the population who are at relatively increased risk of having the disease will ensure successful intervention programmes. However, a good knowledge of the sociodemographic, cultural and environmental risk variables influencing the risk of malaria occurrence is prerequisite to planning targeted allocation of malaria intervention. The study therefore evaluated the sociodemographic, cultural and environmental risk variables influencing the risk of malaria infection occurrence and its distribution patterns.

\section{Materials And Methods}

Lagos is a tropical rainforest zone, consisting of two main vegetation types, namely; swamp forest in the southern coastal belt and dry lowland rain forest in the northern vegetated area of the state (Okorie, 2012). The swamp forest is made up of mangrove forest and coastal vegetation developed under the brackish conditions of the coastal areas and the swamp of the freshwater, lagoons, creeks and estuaries (Nwajide, 2013; Lagos Eko Additional Financing Project, 2013). Lagos exhibit a moderate and stable malaria transmission (mesoendemic) that peaks during the wet season period, which coincides with increase in mosquito population (Aina, et al., 2013). The study was conducted in Epe town, Epe Local Government Areas and Orimedu constituency, IbejuLekki LGA (Fig 1).

The numerous water bodies in Epe justify the popular fishing and other farming activities attributed to the town, being one of the major food source, (especially fish) of the State (Mohammed et al., 2015). The permanent water bodies present, which are of varying size, turbidity, depth and speed of water flow, in the area are the source of the numerous wetlands present in that town (Hassan et al., 2012). These wetlands create favourable habitats for malaria vectors to thrive all year round but with varying intensities. The human settlements that are close to 
these wetlands may likely experience an almost all round the year breeding of mosquitoes (Africa Indoor Residual Spray, 2015), and subsequent malaria transmission (Odugbemi et al., 2016).

Orimedu is home to Yoruba speaking natives, although, there are lots of other people from different parts of the country and the globe living, working and doing business in the area. The area is known for its resource-based economic activities like fishing, agriculture, timber/saw-milling, mat/raffia weaving, oil-palm processing and emerging eco-tourism (Omenai and Ayodele, 2014). Malaria transmission in the area also occur throughout the year with peaks occurring in the rainy season (Odugbemi et al., 2016).

The study is a descriptive cross sectional survey and experimental design, which consists of parasitological and environmental studies. Ethical approvals were obtained from the Lagos State University Teaching Hospital (LASUTH) ethical review board and University of Ibadan/ University College Hospital (UI/UCH) Ethics Committee, IAMRAT, College of Medicine, University of Ibadan. Permissions were obtained from relevant authorities and participants' informed consents were also obtained. A sample size of 360 , which is shared equally among the 2 study LGAs was used for the study. The study participants were household heads (HHs), selected through multistage systematic random sampling technique. The head of each of the selected household was enrolled into the study for oral interview, questionnaire administration, and blood sample collection. The sampling of participants was carried out in the Primary Health Centres (PHCs) in the study LGAs.

The informed consent of selected HHs willing to participate in the study were obtained prior to enrolment into the study. The inclusion criteria used in the enrolment of participants for the study was based on location of the participant household within the study sampling frames, consent to participate and willingness to comply with study requirements and procedures, irrespective of showing symptoms of uncomplicated malaria or mild fever. Individual who does not reside within the sampling frame, or is severely ill, showing gross symptoms of severe diseases like severe malaria or refused to give their informed consent, were excluded from participating in the study.

\section{Oral interview and questionnaire administration}

Pretested and structured questionnaires were administered by an already oriented and trained volunteer medical recorder to each of the 360 selected HHs. Each questionnaire was sought into 3 categories of information, which included; socio-demographic characteristics of respondents and the household members, which includes age, sex, marital status, occupation, education- and income level; mosquito-prevention practices and knowledge about mosquito breeding; and lastly, environmental and behavioural factors of vulnerability to malaria which included presence of: temporary pool (stagnant) of water, gutter for draining used water, thick surrounding vegetation, uncovered bowls and drums filled with water, fish pond/open reservoirs, refuse/waste dump site, window and/or door nets and open septic tanks and/or bathing/used water storage pits.

Blood samples were collected using a $2.5 \mathrm{ml}$ syringe by a volunteer health worker in each of the study PHC. The collected blood samples $(0.25$ to $0.5 \mathrm{ml})$ were immediately transferred into labelled heparinised sample bottles, which were stored in refrigerator for further analysis.

Microscopic procedures were done according to guidelines by WHO (2010). A plastic pipette was used to collect blood sample from the labelled heparinized sample bottle and a single small drop of blood was gently put on the middle of a labelled microscope slide for thin film. 
The thin film was examined under the microscope at x100 magnification to check for the presence and confirmation of malaria parasite species. A different and experienced laboratory technician also examined the slides for quality assurance purpose (WHO, 2009).

Sequel to the conclusion of blood sample collection and questionnaire administration, participants' places of residence were visited for ground truthing, using their addresses and phone numbers used during the enrolment exercise, following a notice of schedule of visit. Groundtruthing was done using a hand held GPS to take the geocoordinates and altitude of participant's residential location. The environmental features of their surrounding residence were also investigated. Environmental features that were investigated in the participants' houses were presence of: temporary (stagnant pool), good drainage, vegetations, open reservoir, modern toilet facility and refuse dumpsite.

\section{Results}

The prevalence of malaria was $32.2 \%$. Participants above 60 years were at highest risk of having malaria $(0 . R=1.35)$ relative to participants between 0 to $15 y$ ears while those between age 46 - 60years had odds ratio of 1.26 (Table 1). The Odds ratios of participants in relation to educational level using no formal education as the reference level were $0.462,2.517$ and 0.806 for primary, secondary and tertiary education levels respectively. Trained employees, traders, civil servants, and pensioners had odd ratios of $2.125,1.836,2.636$, and 3.000 respectively in relation to unemployed participants.

Participants without a previous malaria episode within the last one year prior to the conduct of the study were at relatively higher risk of the disease, $O . R=1.333$ relative to those who did not have a previous episode.

Participants who sought treatment in designated healthcarae facilities were least likely to have malaria, $0 . R=$ 0.000 relative to those who sought treatment in inappropriate places. Participants who are not aware of malaria as a disease were 2.113 times more likely to have malaria. However, participants who were aware of malaria as a vector borne disease were at relatively high risk of having the disease, $0 . R=1.47$ compared with those who weren't knowledgeable at all. Risk of malaria was also found to increase among participants who do not have knowledge about its preventability, O.R $=0.794$ compared with those who had, $O . R=0.543$. A total of two hundred and eight (208), which accounted for $57.8 \%$ of the participants own at least one bed net (Fig. 2). The prevalence of malaria was $33.7 \%$ among participants who possess bednet(s) compared with those who do not $(30.3 \%),{ }^{2}(3)=1.81, P 0.50>0.05$.

Malaria prevalence was relatively higher among participants who do not know at least one standard mosquito prevention practice (33.2\%) compared with those who knew $(30.3 \%),{ }^{2}(3)=1.55$, P0.57>0.05 (Fig 3). Malaria prevalence was $28.8 \%$ among participants who had stagnant pools in their surrounding compared with $33.9 \%$ observed among participants who don't have, ${ }^{2}(3)=1.17, \mathrm{P} 0.33>0.05$. Sixty-three percent of the participants do not have closed windows and or door nets (fig 5). Malaria prevalence was insignificantly higher among participants with closed windows and or door nets (32.4\%) compared with participants who do not have (32.1), ${ }^{2}(3)=2.33, P 0.95>0.05$.

\section{Discussion}


Bello and Hassan (2017) had previously reported a slightly higher prevalence (36.1\%) in Epe. The decline in prevalence may be attributed to the impact of malaria control interventions used since the past years (Bhatt et al., 2015). Malaria prevalence has long been established to be age dependent (WHO, 2019), with older children (>5yrs) having higher tendency of having the disease (Bousema and Drakeley, 2017), possibly due to reduced intervention rate, late sleeping habit and increased attractiveness to mosquitoes (Thomson et al. 1996; Kulkarni et al., 2010; Moiroux et al., 2012). This study conformed to the above hypothesis as prevalence was highest (50\%) among participants between 5 and $15 y$ rs.

Malaria incidence was previously reported to decrease with decrease in maternal education level (WHO, 2012). The low malaria prevalence observed among those with primary and tertiary education re-emphasizes the significant influence of education on malaria. However, high likelihood of participants with secondary education $(0 . R=2.5)$ of having malaria in this study may be due to factors such as reduced intervention rate, late sleeping habit and increased attractiveness to mosquito (Bousema and Drakeley, 2017).

High malaria prevalence that was observed among the employed may be due to high rate of exposure to repeated mosquito bites (Ramdzan et al., 2019). However, low immunity may be the cause of high prevalence among the pensioners. High likelihood of malaria infection ( $O . R=1.33$ ) observed among participants without a previous episode may be due to non-consumption of antimalarial drugs (Drakeley et al., 2017), since the participants may likely not show any sign of malaria, thereby giving room for the persistence of the parasite in the body. Seeking treatment in appropriate designated facilities such as healthcare centers and pharmacy store promote total parasite clearance. This explains the low likelihood of having malaria in these category of participants.

The impact of good knowledge about mosquito prevention practices and adoption of one or more of the practices on malaria incidence (Bello and Hassan, 2018) cannot be over-emphasized in this study. A study showed that individuals who have mosquito nets in their rooms, have less chance of having household members testing positive for RDT (Ayele et al., 2013). However, high malaria prevalence observed among those who own a bed net may imply that owning a bed net does not translate to usage.

Low malaria prevalence among those having knowledge about one or more standard mosquito prevention practices, implies that knowing and adopting one or more standard mosquito prevention practices is likely to reduce malaria incidence Several studies have hypothesized that environmental features and behavioural factors of vulnerability to malaria may be significant risk factors for malaria (Nkuo-Akenji et al., 2006; Kokwaro, 2009; Messina et al., 2011; Kimbi et al., 2013).

Analysis showed that there was spatial correlation of malaria incidence with environmental factors in India. Villages under malaria hotspots are characterised with abundant water bodies (Handique et al., 2016). However, this was contrary to this study as malaria prevalence was lower among participants who had stagnant pools and relatively higher among those having window/door net in their homes. This may imply that other risk factors such as good case management of malaria, IRS, among other are also crucial in malaria transmission. In addition, the observed difference in prevalence rate might have occurred by chance since it was not statistically significant.

\section{Conclusion}


Sociodemographic and cultural risk factors for malaria include Age, educational level, occupation, previous malaria episode, treatment facility, malaria awareness and preventability. Knowledge about standard mosquito prevention practices is a better predictor of malaria occurrence compared to other risk variables such bednet ownership, environmental surrounding and closed windows/door nets.

\section{Declarations}

\section{Funding}

No funds, grants, or other financial supports was received for the conduct of this research.

\section{Conflict of interest}

There is no conflict of interest.

\section{Availability of data}

All the data used for the research work are available and will be reproduced upon request.

\section{Author's contributions}

The conceivement, design and performance of the research, Bayesian Geostatistical analysis and the preparation and writing of the manuscript were done by Bello Abdulrahman Babatunde

\section{Ethics approval}

Ethical approval to undertake the study was obtained from the Lagos State University Health Research and Ethics Committee (NHREC04/04/2008), with approval number; LREC/06/10/1315 The study was performed in accordance with the ethical standards as laid down in the 1964 Declaration of Helsinki.

\section{Consent to participate}

Informed consents were obtained from the participants prior to enrollment into the study.

\section{Consent to participate}

Data obtained from participants were coded for confidentiality and they all consented to publication of the research findings.

\section{Contribution to knowledge}

- This study did not identify surrounding stagnant pools, bednet(s) or closed windows/door nets as risk factor that individually influence malaria incidence. For instance, living in closed windows/doors but not sleeping under mosquito treated bednet does not guarantee malaria absence

- This implies that multiple sociodemographic, cultural and environmental risk factors collectively influence the outcome of malaria and should all be put into consideration when designing malaria intervention programmes. 


\section{References}

1. Adepoju KA, Akpan GE (2017) Historical Assessment of Malaria Hazard and Mortality in Nigeria- Cases and Deaths: 1955-2015. International Journal of Environmental Bioenergy 12(1):30-46

2. Aina OO, Agomo CO, Olukosi YA, Okoh HI, Iwalokun BA et al (2013) Malariometric Survey of Ibeshe Community in Ikorodu, Lagos State: Dry Season. Malaria Research and Treatment. http://dx.doi.org/10.1155/2013/487250

3. AIRS (2015) Nigeria Final Entomology Report. November 2014 - December 2015, Africa Indoor Residual Spraying Project. Abt Associates Inc

4. Dawaki S, Al-Mekhlafi HM, Ithoi I, Ibrahim J, Atroosh WM et al (2016) Is Nigeria winning the battle against malaria? Prevalence, risk factors and KAP assessment amonog Hausa communities in Kano State. Malaria Journal 15:351

5. Ernst KC, Lindblade KA, Koech D, Sumba PO, Kuwuor DO et al (2009) Environmental, socio-demographic and behavioural determinants of malaria risk in the western Kenyan highlands: a case-control study. Tropical Medicine International Health 14:1258-1265

6. Hassan B (2012) A study of inland waterways transport in Epe area of Lagos. B.Sc project, Department of Geography and Planning Science. Adekunle Ajasin University, Akoko, Ondo State, xi + 77

7. Havlicek J, Roberts SC, Flegr J (2005) Women's preference for dominant male odour: effects of menstrual cycle and relationship status. Biology Letters 1(3):256-259

8. Jamison DT, Mosley WH, Measham AR, Bobadilla A (1993) Disease control priorities in Developing countries. Summary and Cross-Cutting Themes: Investing in Health. Jamison, D.T., Breman, J.G., Measham, A.R., Alleyne, G., Claeson, M., Evans, D.B., Prabhat, J. et al. 2nd edn. New York: A copublication of Oxford University Press and The World Bank. pp 3-34

9. Koram KA, Bennett S, Adiamah JH, Greenwood BM (1995) Socioeconomic risk-factors for malaria in a periurban area of the Gambia. Transactions of the Royal Society of Tropical Medicine Hygiene 89:146-150

10. Lagos Eko additional financing project (2013) Environmental and social management framework (ESMF): Draft report December 2013. EnvironQuest. Last accessed online at https://documents.shihang.org

11. Lindsay S, Ansell J, Selman C, Cox V, Hamilton K, Walraven G (2000) Effect of pregnancy on exposure to malaria mosquitoes. Lancet. 355:1972

12. Mohammed US, lyiola AS, Usman RK (2015) Production analysis of catfish farming in Epe Local Government Area of Lagos State. Production Agriculture Technology 11(2):153-161

13. Nwajide CS (2013) Geology of Nigeria's Sedimentary Basins. CSS Bookshops Ltd, Lagos, Lagos, 565pp

14. Nwaneli El, Eguonu I, Ebenebe JC, Osuorah CDI, Ofiaeli OC, Nri-Ezedi CA (2020) Malaria prevalence and its sociodemographic determinants in febrile children - a hospital based study in a developing community in South-East Nigeria. Journal of Preventive Medicine Hygiene 61:E173-E180

15. Odugbemi BA, Wright KO, Onajole AT, Kuyinu YA, Goodman OO, Odugbemi TO, Odugbemi OO (2016) A malariometric survey of under-fives residing in indoor residual spraying-implementing and nonimplementing communities of Lagos, Nigeria. Malaria Journal 15:458

16. Ojiezeh TI, Ibeh NI, Opedun DO, Udoh SJ (2010) Malaria Endemicity among Pregnant Women in Urban and Semi-Urban Areas in Southwest, Nigeria. American-Eurasian Journal of Scientific Research 5:207-211 
17. Okorie FC (2012) A spatio-temporal analysis of deforestation in Epe and its environs, Lagos, Nigeria. International Journal of Science Environment Technology 1(5):548-562

18. Pascual M, Ahumada JA, Chaves LF, Rodo X, Bouma M (2006) Malaria resurgence in the East African highlands: temperature trends revisited. Proc Natl Acad Sci USA 103(15):5829-5834

19. Peterson I, Borrell LN, El-Sadr W, Teklehaimanot A (2009) Individual and household level factors associated with malaria incidence in a highland region of Ethiopia: a multilevel analysis. American Journal of Tropical Medicine Hygiene 80:103-111

20. Rejmankova E, Roberts DR, Pawley A, Manguin S, Polanco J (1995) Predictions of adult Anopheles albimanus densities in villages based on distances to remotely sensed larval habitats. Am J Trop Med Hyg 53:482-488

21. Thomson MC, Connor SJ, Milligan PJ, Flasse SP (1996) The ecology of malaria - as seen from earth observation satellites. Annals of Tropical Medicine Parasitology 90:243-264

22. Tolulope $O$ (2014) Spatio-Temporal Clustering of Malaria Morbidity in Nigeria (2004-2008). Journal of Science Research 13:99-113

23. Torr SJ, Mangwiro TN, Hall DR (2006) The effects of host physiology on the attraction of tsetse (Diptera: Glossinidae) and Stomoxys (Diptera: Muscidae) to cattle. Bulletin of Entomological Research 96:71-84

24. Trape JF, Lefebvre-Zante E, Legros F, Ndiaye G, Bouganali H, Druilhe P, Salem G (1992) Vector density gradients and the epidemiology of urban malaria in Dakar, Senegal. American Journal of Tropical Medicine Hygiene 47:181-189

25. WHO (2009) Malaria microscopy quality assurance manual. World Health Organisation, regional office for the western pacific

26. WHO (2010) Basic malaria microscopy, Part I. Learner's guide. Geneva, Switzerland

\section{Tables}


Table 1

Odds ratios of human related potential risk factors affecting the occurrence malaria infection

\begin{tabular}{|c|c|c|c|c|c|c|c|}
\hline \multirow[t]{2}{*}{ Parameter } & \multirow[t]{2}{*}{ Category/Class } & \multirow{2}{*}{$\begin{array}{l}\text { Total } \\
\text { population }\end{array}$} & \multirow{2}{*}{$\begin{array}{l}\text { malaria } \\
\text { positives }\end{array}$} & \multirow{2}{*}{$\begin{array}{l}\text { Prevalence } \\
\text { (\%) }\end{array}$} & \multirow{2}{*}{$\begin{array}{l}\text { Odds } \\
\text { Ratio }\end{array}$} & \multicolumn{2}{|c|}{ 95\% C.I } \\
\hline & & & & & & Lower & Upper \\
\hline \multirow[t]{4}{*}{ Age (years) } & $6-15$ & 2 & 1 & $50.0 \%$ & 1 & & \\
\hline & $16-45$ & 285 & 92 & $32.3 \%$ & 0.6 & 0.027 & 13.582 \\
\hline & $46-60$ & 65 & 20 & $30.8 \%$ & 1.259 & 0.294 & 5.381 \\
\hline & Above 60 & 8 & 3 & $37.5 \%$ & 1.35 & 0.294 & 6.205 \\
\hline \multirow{4}{*}{$\begin{array}{l}\text { Educational } \\
\text { level }\end{array}$} & No formal education & 5 & 2 & $40.0 \%$ & 1 & & \\
\hline & Primary & 34 & 5 & $14.7 \%$ & 0.462 & 0.059 & 3.639 \\
\hline & Secondary & 247 & 88 & $35.6 \%$ & 2.517 & 0.826 & 7.671 \\
\hline & Tertiary & 74 & 21 & $28.4 \%$ & 0.806 & 0.418 & 1.553 \\
\hline \multirow[t]{8}{*}{ Occupation } & Unemployed & 6 & 3 & $50.0 \%$ & 1 & & \\
\hline & Trained employee & 100 & 32 & $32.0 \%$ & 2.125 & 0.406 & 11.115 \\
\hline & Trader & 156 & 55 & $35.3 \%$ & 1.836 & 0.358 & 9.407 \\
\hline & Civil servant & 40 & 11 & $27.5 \%$ & 2.636 & 0.461 & 15.085 \\
\hline & Student/Apprehentice & 33 & 9 & $27.3 \%$ & 2.667 & 0.452 & 15.220 \\
\hline & Housewife & 17 & 5 & $29.4 \%$ & 2.400 & 0.355 & 16.213 \\
\hline & Pensioner & 4 & 1 & $25.0 \%$ & 3.000 & 0.188 & 47.963 \\
\hline & Others & 4 & 0 & $0.0 \%$ & 0.000 & 0.000 & \\
\hline \multirow{2}{*}{$\begin{array}{l}\text { Malaria } \\
\text { episode }\end{array}$} & Yes & 178 & 63 & $35.4 \%$ & 1 & & \\
\hline & No & 182 & 53 & $29.1 \%$ & 1.333 & 0.856 & 2.077 \\
\hline \multirow{6}{*}{$\begin{array}{l}\text { Treatment } \\
\text { facility }\end{array}$} & Others & 1 & 1 & $100.0 \%$ & 1 & & \\
\hline & Traditional healer & 9 & 3 & $33.3 \%$ & 0.405 & 0.047 & 3.518 \\
\hline & Pharmacy & 53 & 16 & $30.2 \%$ & 0.400 & 0.031 & 5.151 \\
\hline & At home & 31 & 9 & $29.0 \%$ & 0.462 & 0.05 & 4.283 \\
\hline & No where & 6 & 1 & $16.7 \%$ & 0.489 & 0.05 & 4.793 \\
\hline & Health facility & 260 & 86 & $33.1 \%$ & 0.000 & 0.000 & \\
\hline $\begin{array}{l}\text { Malaria } \\
\text { Awareness }\end{array}$ & Yes & 358 & 115 & $32.1 \%$ & 1 & & \\
\hline
\end{tabular}




\begin{tabular}{|c|c|c|c|c|c|c|c|}
\hline \multirow[t]{2}{*}{ Parameter } & \multirow[t]{2}{*}{ Category/Class } & \multirow{2}{*}{$\begin{array}{l}\text { Total } \\
\text { population }\end{array}$} & \multirow{2}{*}{$\begin{array}{l}\text { malaria } \\
\text { positives }\end{array}$} & \multirow{2}{*}{$\begin{array}{l}\text { Prevalence } \\
\text { (\%) }\end{array}$} & \multirow{2}{*}{$\begin{array}{l}\text { Odds } \\
\text { Ratio }\end{array}$} & \multicolumn{2}{|c|}{$95 \%$ C.I } \\
\hline & & & & & & Lower & Upper \\
\hline & No & 2 & 1 & $50.0 \%$ & 2.113 & 0.131 & 34.083 \\
\hline \multirow{3}{*}{$\begin{array}{l}\text { Vector } \\
\text { borne? }\end{array}$} & Don't know & 93 & 29 & $31.2 \%$ & 1 & & \\
\hline & Yes & 232 & 73 & $31.5 \%$ & 1.471 & 0.657 & 3.294 \\
\hline & No & 35 & 14 & $40.0 \%$ & 1.452 & 0.699 & 3.016 \\
\hline \multirow[t]{3}{*}{ Preventability } & Don't know & 37 & 15 & $40.5 \%$ & 1.000 & & \\
\hline & Yes & 286 & 91 & $31.8 \%$ & 0.543 & 0.204 & 1.445 \\
\hline & No & 37 & 10 & $27.0 \%$ & 0.794 & 0.369 & 1.709 \\
\hline
\end{tabular}

Figures 

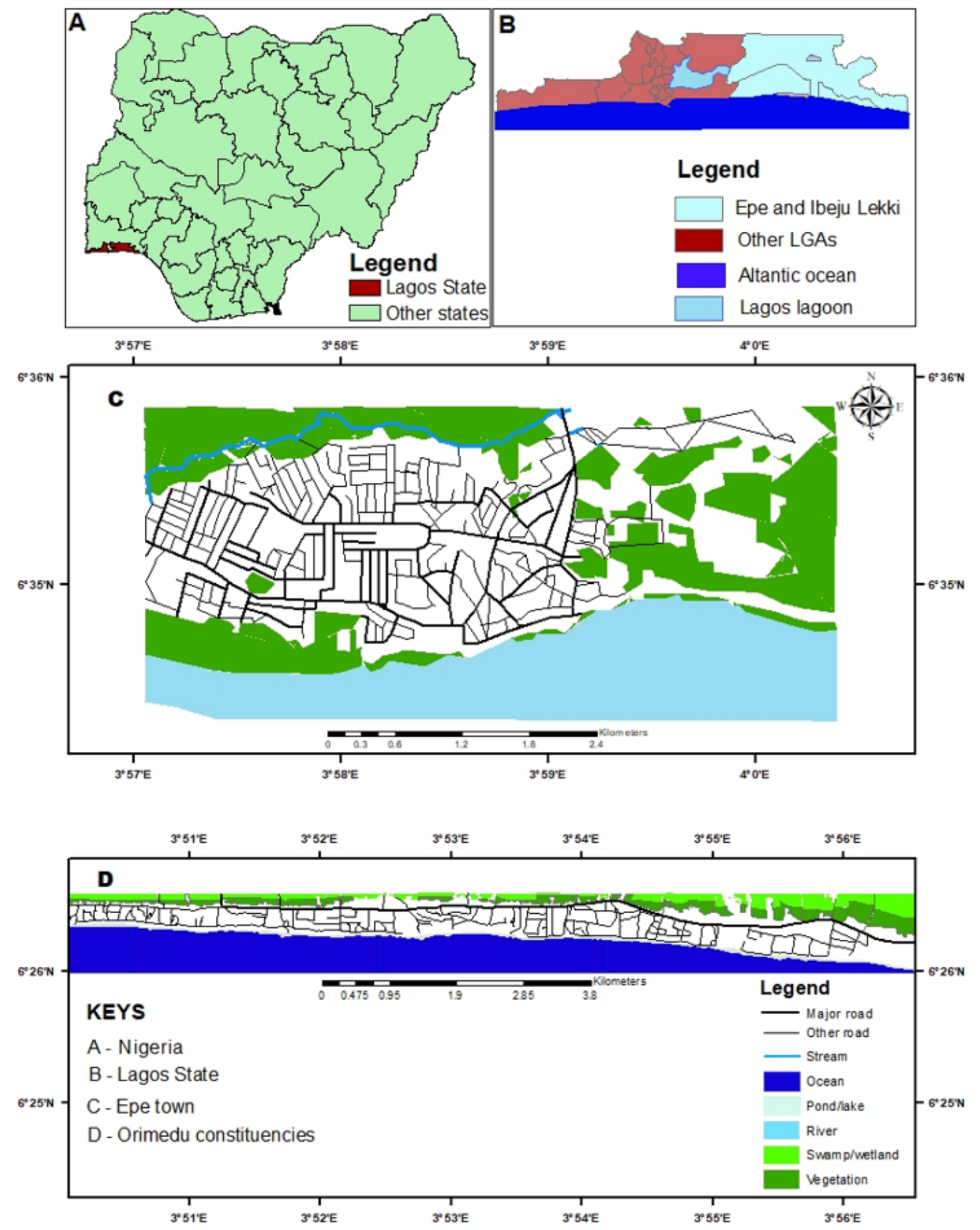

\section{Figure 1}

Map of Nigeria showing the locations of Epe and Ibeju Lekki LGAs in Lagos State Note: The designations employed and the presentation of the material on this map do not imply the expression of any opinion whatsoever on the part of Research Square concerning the legal status of any country, territory, city or area or of its authorities, or concerning the delimitation of its frontiers or boundaries. This map has been provided by the authors. 


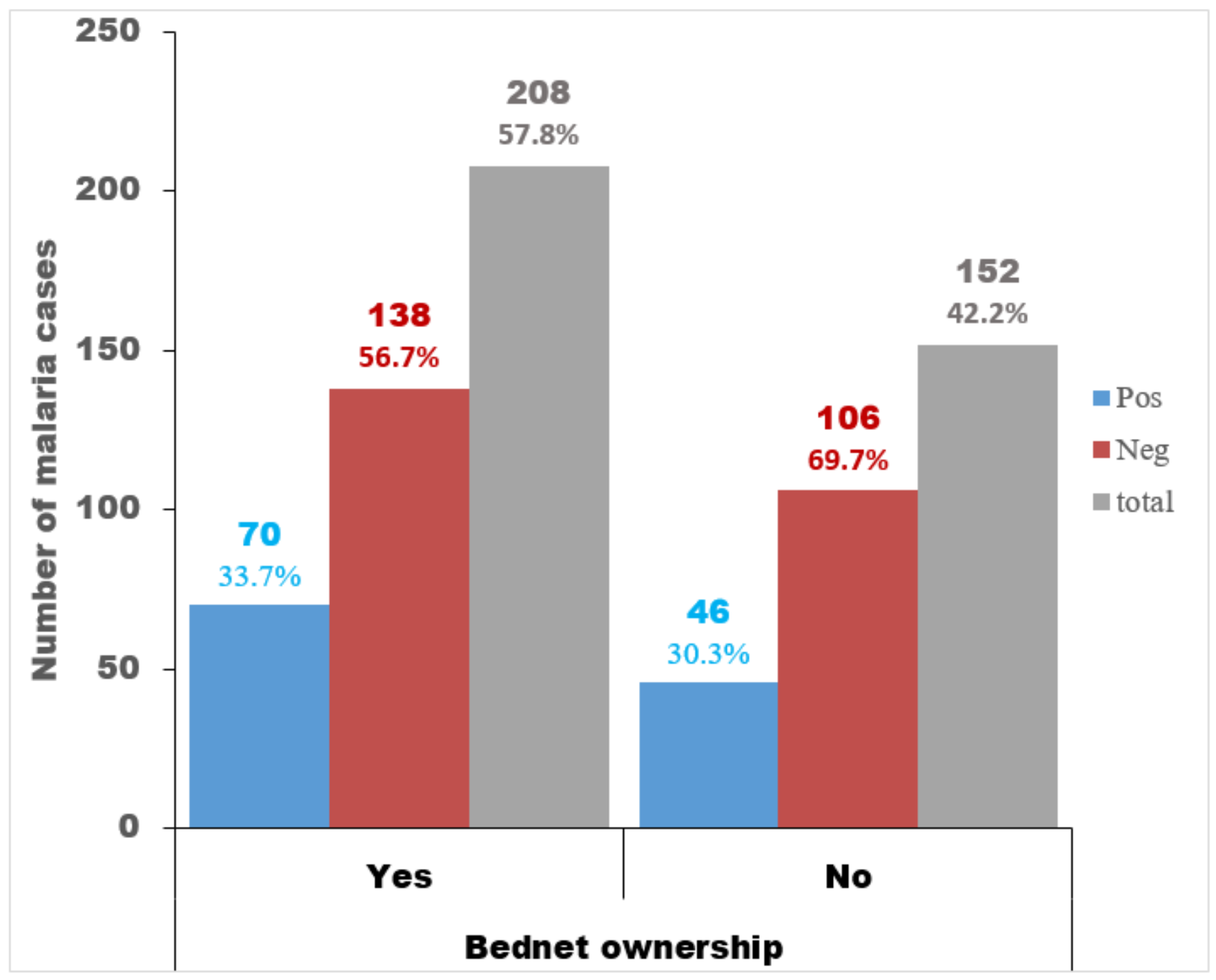

Figure 2

Relationship between malaria prevalence and bed net ownership 


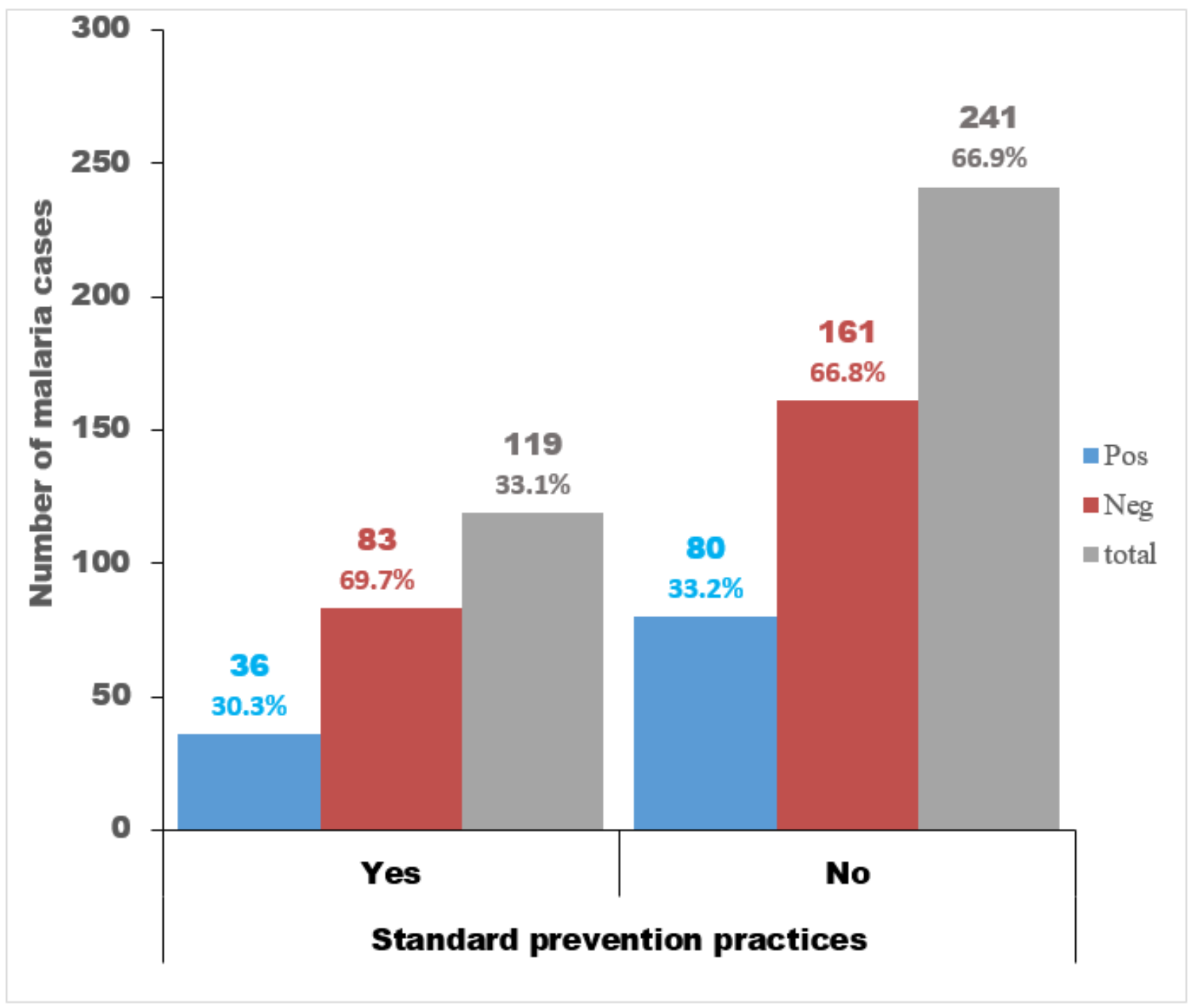

Figure 3

Relationship between malaria prevalence and knowledge about standard mosquito prevention practices 


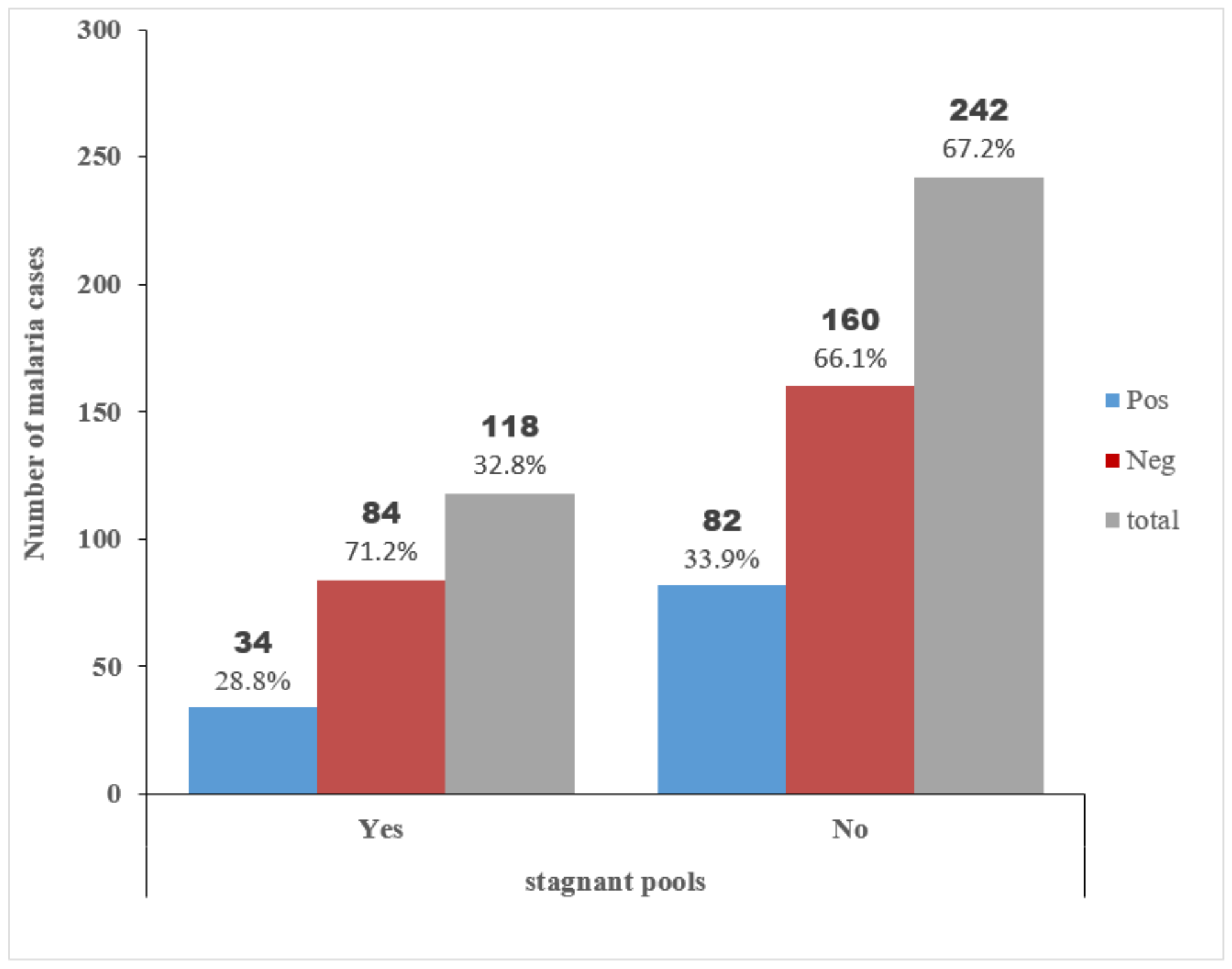

Figure 4

Relationship between malaria prevalence and surrounding stagnant pools on malaria outcome 


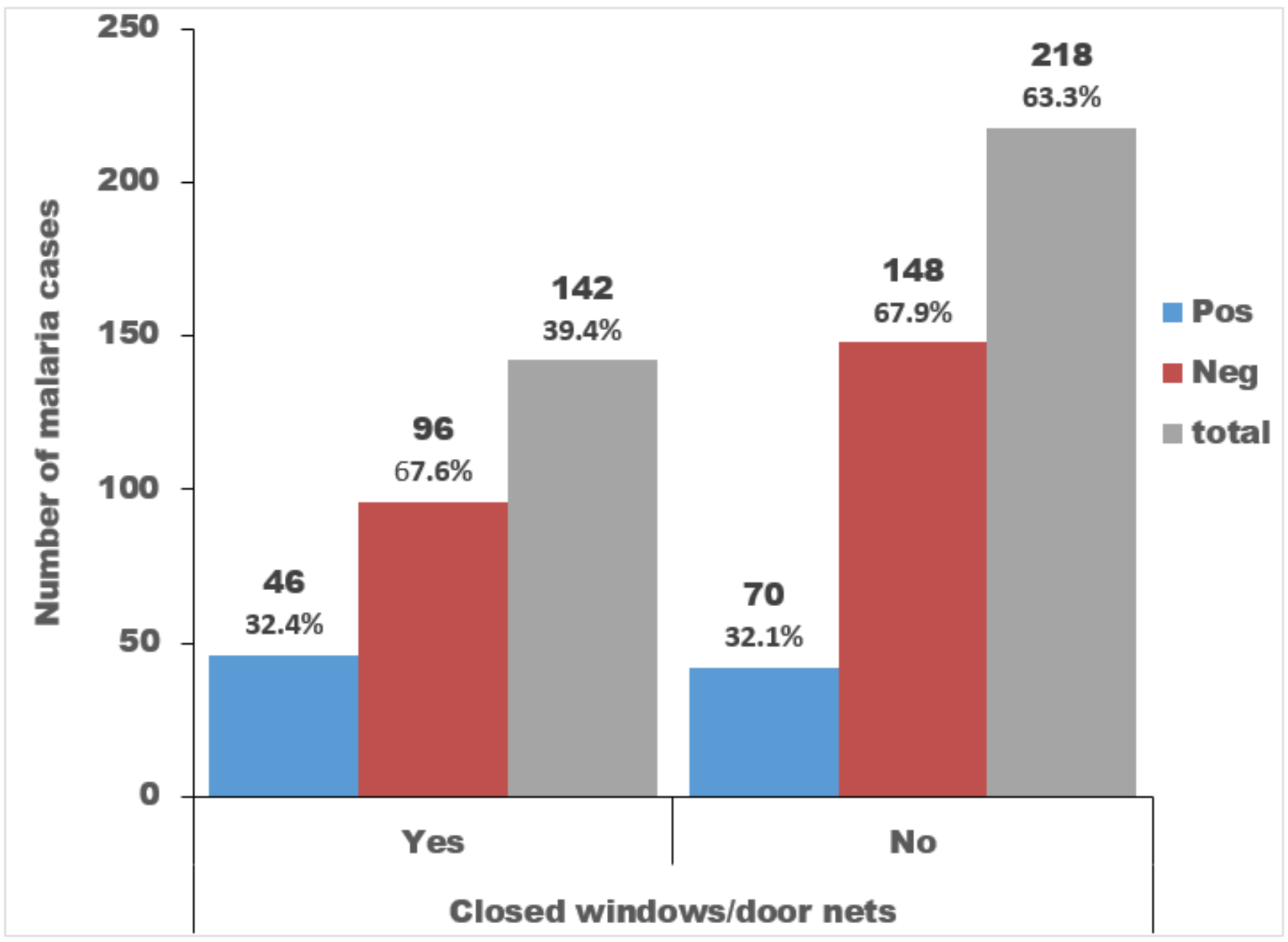

Figure 5

Relationship between malaria prevalence and presence of closed windows/ door nets 


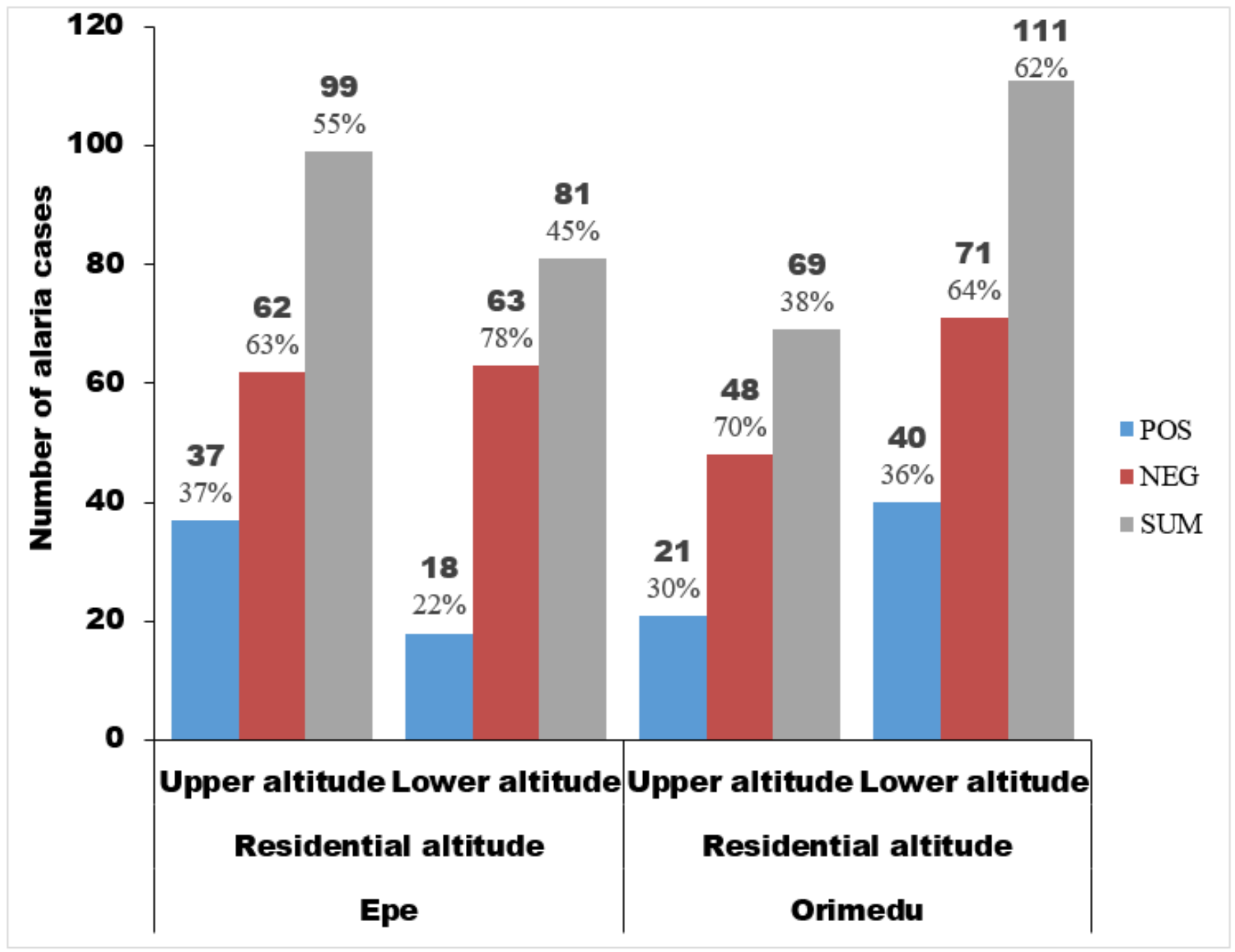

Figure 6

Prevalence of malaria in relation to altitude of participants' residences 